BMJ Open Ophthalmology

\title{
Ocular surface angiography: from neovessels to neoplasia
}

\author{
Bernhard Steger
}

To cite: Steger B. Ocular surface angiography: from neovessels to neoplasia. BMJ Open Ophthalmology 2021;8:e000829. doi:10.1136/ bmjophth-2021-000829

Received 11 June 2021 Accepted 21 July 2021
Check for updates

\section{(c) Author(s) (or their} employer(s)) 2021. Re-use permitted under CC BY-NC. No commercial re-use. See rights and permissions. Published by BMJ.

Department of Ophthalmology, Medizinische Universitat Innsbruck, Innsbruck, Austria

\section{Correspondence to} Dr Bernhard Steger; bernhard. steger@i-med.ac.at

\section{ABSTRACT}

The ocular surface vascular system plays a key role in corneal and conjunctival inflammatory, infectious and neoplastic pathology. Angiographic vessel analysis using intravenous dyes and optical coherence tomography technology allow both the quantitative and functional assessment of conjunctival vasculature and corneal neovessels. Based on a thorough understanding of vascular alterations in ocular surface disease, angiographic assessment facilitates the clinical management of corneal neovascularisation, the grading of ocular surface inflammation and the identification of tumour angiogenesis in dysplastic or malignant lesions. This review summarises key aspects of the clinical application of corneal and conjunctival angiography as presented at the 2021 virtual Bowman Club meeting.

\section{INTRODUCTION}

The ocular surface (OS) comprises four main component areas: the normally clear and avascular cornea, the conjunctiva, the limbus and the tear film. Vasculature normally covers the entire OS except for the cornea, although it does extend into the corneal periphery with both a haematic and lymphatic marginal corneal arcade. ${ }^{1}$ Blood supply and lymphatic drainage of these tissues are interdependent, change significantly in health (ie, with age) and disease, and are essential for the homoeostasis of the cornea and conjunctiva. Vasculature delivers nutrients, removes catabolites and aids the defence responses of the OS to infectious, inflammatory, traumatic and neoplastic disease. ${ }^{2}$ The development, application and monitoring of treatments for vascular abnormalities depends on the in vivo analysis of the OS vasculature. Corneal and conjunctival angiography using the fluorescent dye fluorescein was introduced in the 1970s, but the dependence on analogue noncomputerised systems limited the quality and analysis of the images. The introduction of digitalised corneal angiography, using both fluorescein angiography (FA) and in particular indocyanine green angiography (ICGA) has been a major breakthrough for evaluating OS vasculature, allowing both the quantitative and functional assessment of conjunctival vasculature and corneal neovessels. FA and ICGA are superior to biomicroscopic assessment of corneal neovascularisation $(\mathrm{CoNV}),{ }^{3}{ }^{4}$ enable staging and treatment planning of $\mathrm{CoNV}^{5}{ }^{6}$ allow the objective grading of conjunctival inflammation, ${ }^{78}$ and provide useful non-invasive tool to assess and grade OS tumours. ${ }^{9}{ }^{10}$ The aim of this review is to provide an overview of the clinical applicability of FA and ICGA for the assessment of CoNV and OS neoplastic lesions.

\section{ANGIOGRAPHIC ASSESSMENT OF CORNEAL NEOVESSELS}

CoNV is always pathological because the cornea in its physiological state is avascular. In a state of health, an equilibrium of proangiogenic and antiangiogenic factors prevents the formation of CoNV. CoNV forms as a response to injury and is characterised by abnormal vessel architecture affecting predominantly interendothelial cell tight junctions and pericyte ensheathment, associated with transvascular exudation in both immature and stabilised states. ${ }^{11} 12$

An experiment by Sivak et al identified two phases of corneal angiogenesis. ${ }^{13}$ Initial angiogenesis is due to increased levels of vascular endothelial growth factor (VEGF), which is directly secreted from corneal repair epithelial cells. Subsequent angiogenesis occurs due to the inflammatory cascade initiated by proinflammatory cytokines released by the same cells. While the initial stimulus is therefore VEGF-dependant and independent from inflammation, it is only later (after day 3) that the inflammatory cascade evolves and causes increased angiogenesis. VEGF-A has been identified as the key member of the family. It interacts with the greatest affinity to VEGF receptors 1 and 2 , which are expressed on limbal vascular endothelial cells and when bind to VEGF-A form a proangiogenic stimulant, promoting both corneal blood and lympohangiogenesis. ${ }^{11}$ A soluble (non-membrane associated) form of VEGF receptor 1 is situated in the extracellular space of the cornea. It is able to bind to VEGF-A and form an antiangiogenic 
stimulant, acting as a buffer system to maintain corneal avascularity. It has been shown, that VEGF receptor 1 expression is selectively suppressed in corneal epithelial cells in herpes simplex keratitis, which explains rapid and aggressive corneal angiogenesis observed especially in this type of infectious keratitis. ${ }^{14}$

Despite the detrimental effect of CoNV on corneal clarity and surface regularity, it has been observed that clinical stabilisation of herpes simplex keratitis correlates with the time of vessel stabilisation, suggesting a role of angiogenesis in the immune response, resolution of infectious keratitis and subsequent corneal healing. Maruyama et al showed that macrophages in the bloodstream infiltrate areas of inflammation and become activated, secreting TNF-alpha and VEGF, thereby inducing haemangiogenesis and lymphangiogenesis. ${ }^{15}$ It has also been determined that these blood and lymphatic vessels are closely related to the process of wound healing and the resolution of bacterial keratitis ${ }^{16}$ and that they decrease oedema and inflammation in bacterial keratitis. ${ }^{17} 18$ Despite these positive effects, the presence of $\mathrm{CoNV}$ in a recipient corneal bed is an important risk factor for corneal allograft rejection. ${ }^{12}$ The extent of vascularisation of the recipient cornea at the time of corneal transplantation correlates strongly with the risk of graft rejection and failure. Similarly, vascularisation of the graft in the postoperative period is also associated with an increased risk of graft failure. ${ }^{19}$

While the clinical assessment of patients undergoing keratoplasty focuses mainly on the presence of corneal haematic vessels, it is now known, that coexistent, but biomicroscopically invisible, corneal lymphatic vessels are in fact the principal mediators of corneal graft rejection. ${ }^{20}$ Dierich et al where able to show in a murine model, that the risk of corneal graft rejection in both haemvascularised and avascular corneal beds was not significantly different, while risk was significantly increased in graft beds with both blood and lymphatic vascularisation. In a similar model Hos and coworkers showed that the blockade of corneal lymphangiogenesis using VEGFR-tyrosine kinase inhibitor ZK 261991 resulted in improved graft survival after corneal transplantation. Consequently, clinically feasible lymphangioregressive approaches have successfully been implemented for the preconditioning treatment of corneal graft beds to decrease corneal lymphatic vessels, including fineneedle diathermy ${ }^{621}$ VEGF inhibition, ${ }^{22}{ }^{23}$ photodynamic therapy ${ }^{1724}$ and corneal collagen cross-linking. ${ }^{25}{ }^{26}$ While these clinical measures may reduce the risk of corneal graft rejection in high-risk keratoplasty, it remains clinically impossible to verify individual lymphangioregressive treatment efficacy due to a lack of feasible imaging methods to visualise corneal lymphatic vessels.

A thorough understanding of the time course of corneal blood and lymphatic angiogenesis or angioregression is therefore clinically important. While both corneal blood and lymphatic vessels contemporaneously grow onto the cornea following an inciting event, subsequent vessel regression is different in that lymphatic vessels regress more rapidly over time. Cursiefen et al have shown that lymphatic vessels are present in all excised vascularised corneal buttons with CoNV aged less than 3 months, while no lymphatic vessels were detectable on immunohistochemical analysis in corneas with neovascularisation aged more than 60 months. ${ }^{27}$ So age and the clinical stage of corneal haematic neovessels can serve as an indirect indicator of lymphatic vessel presence in a future graft bed.

However, precise clinical staging of CoNV from appearance is difficult. A five-point staging scale has been proposed, but the authors acknowledge that the differentiation of stages 2-4 is clinically difficult and not reproducible. ${ }^{28}$

Intravenous angiography allows the objective quantitative and functional assessment of CoNV. ICGA reliably depicts CoNV and any change of area of vascularisation, even in the presence of corneal opacification. ${ }^{3}$ ICGA enables the identification of corneal feeder vessels for subsequent angiography-guided selective arteriolar fineneedle diathermy. ${ }^{6}$ Fluorescein dye, on the other hand, readily leaks from vasculature. The time to leakage and the extent of leakage have been shown to correlate with vessel maturity and disease activity in both corneal and conjunctival inflammatory disease. 7 More recently, Palme et al were able to demonstrate late leakage of ICG dye from active but not inactive or regressed CoNV, adding ICGA as a feasible tool to objectively stage CoNV. ${ }^{5}$ ICG leakage from young active vessels was characterised by a more focal leakage pattern compared with fluorescein leakage, presumable at locations of active angiogenesis with endothelial fenestrations large enough allow transvascular leakage of albumin-bound ICG. ${ }^{29}$

Of interest, ICG leakage was observed only in CoNV aged less than 3 months, matching the time of lymphatic vessel regression in vascularised corneas.

These data suggest that the presence of ICG leakage from CoNV is associated with vessel immaturity and the presence corneal lymphatic vessels. Preliminary data analysis of an ongoing study confirmed a significant correlation between ICG leakage in vascularised corneas of patients undergoing keratoplasty and the presence of lymphatic vessels, suggesting ICG leakage as an indirect indicator for risk assessment of vascularised corneal graft beds. $^{30}$

More recently optical coherence tomography (OCT) technology has been used to assess CoNV. ${ }^{31}$ OCT angiography (OCTA) offers a fast and non-invasive approach to depict OS vasculature and yields excellent depth information even in the presence of scars or other corneal opacification. As a continuously evolving OCT application, however, it is still currently limited by severe artefacts, small field-width, and inferior overall image quality compared with ICGA. ${ }^{32}$ Additionally, it lacks information on flow direction for planning of selective afferent fine-needle diathermy, and any functional information on maturity and vessel activity. While OCTA 
currently is not an alternative to intravenous angiography, fast technological progress and the integration of deep learning algorithms into the analysis of vascular networks is expected to widen its applicability for OS angiography in the future.

\section{ANGIOGRAPHIC ASSESSMENT OF OS TUMOURS}

Tumour cells are nourished by diffusion in early stages but at some point require and build up their own vascularisation. ${ }^{33}$ Pathological angiogenesis is a hallmark of tumour growth. Vascular architecture is abnormal and associated with a loss of regularity, heterogeneous vascular densities, ${ }^{34} 35$ blind ending capillaries and the formation of shunt vessel. ${ }^{36}$ High densities of new vessel formation in neoplastic tissues are associated with aggressive invasive growth and metastatic disease. ${ }^{37}$ Both vascular architecture and function are impaired in malignant neoplastic disease. Defective angiogenesis leads to an anomalous vessel wall structure with multilayered basement membrane, and incomplete or loose pericyte coverage associated to chronic transvascular hyperpermeability. ${ }^{38}$

The in vivo observation of tumour angiogenesis is difficult and can be achieved in an experimental setting using intravital microscopy, where the tissue of interest is visualised through a surgically implanted glass window. ${ }^{38}$ OS tumours allow a direct and unaltered biomicroscopic view on human tumour angiogenesis in vivo. A variety of neoplastic lesions develop within OS tissues. The most common types of malignant OS lesions (OSL) include conjunctival intraepithelial neoplasia (including carcinoma in situ), invasive squamous cell carcinoma ${ }^{39}$ and melanocytic lesions such conjunctival melanocytic intraepithelial neoplasia with or without atypia and melanoma. ${ }^{40}$

Clinical assessment of OSL includes the identification of risk factors associated with dysplastic or malignant disease, including increased size and thickness or vascular features such as the presence of haemorrhage, feeder vessels or visible intrinsic tumour vasculature ${ }^{41}{ }^{42}$ Despite these risk factors for malignancy, the highly variable clinical presentation of OSL makes it often impossible to reliably exclude dysplastic or malignant disease from clinical appearance only. ${ }^{41}$ Therefore, current diagnosis largely depends on invasive excisional biopsy and subsequent histological analysis. ${ }^{943}$

Intravenous angiography has proven helpful for the clinical assessment of OSL. On ICGA, afferent feeders can clearly be discerned from efferent vessels. ${ }^{44}$ Due to the frequent intralesional formation of shunt vessels, flow velocity and vessel diameter in efferent venules are increased, bypassing the capillary system. ${ }^{45}$ Consequently, flow and pressure differences between arterioles and venules are reduced, leading to morphologically similar appearance of these vessels, as shown by Brunner et $a l^{44}$ The authors report that the vessel diameter ratio of afferent to efferent vessels was significantly different between benign and malignant melanocytic OSL and that the angiographic filling time was significantly shorter in benign and non-invasive lesions compared with invasive melanocytic and squamous cell OSL. ${ }^{44}$ In a further recent study on squamous OSL, the authors report focal or seafan-shaped intratumoural and conjunctival feeding vessels on ICGA. Angiography proved useful to monitor vessel regression as a measure of treatment response to subconjunctival and perilesional 5-fluorouracil injection. $^{46}$

Additionally, the observation of ICG dye leakage has proved to be useful in the diagnostic evaluation of OSL. While ICG does not usually leak from conjunctival vessels, a recent report describes extensive ICG leakage from intrinsic but not feeding conjunctival tumour vessels or surrounding healthy conjunctival tissues in a case of in situ conjunctival squamous carcinoma. ${ }^{47}$ An example of FA and ICGA in a case of in situ conjunctival squamous carcinoma is given in figure 1. Likewise, the extravascular leakage of ICG was significantly associated with conjunctival melanoma in a series of 30 cases of melanocytic OSL. ${ }^{10}$ The mean time to leakage was less than $1 \mathrm{~min}$ in in situ or invasive melanoma, but almost $6 \mathrm{~min}$ in conjunctival naevi or C-MIN without atypia. No leakage was observed from benign lesions without intrinsic vasculature and only very late leakage in benign lesions with intrinsic vasculature. In melanoma, both diffuse and focal leakage patterns were noted, with focal leakage preceding diffuse leakage in locations of active angiogenesis. The reported increased dye leakage on intravenous angiography in malignant lesions can be explained by transvascular hyperpermeability in tumour vessels ${ }^{48}$ due to pathological tumour angiogenesis with incomplete or absent pericyte coverage and abnormal basement membrane structure. ${ }^{49}$

However, the use of dye leakage behaviour for grading of OSL may be biased by conjunctival inflammation. In an ongoing study and unpublished study by our group, the presence of ICG leakage is therefore correlated with immunohistochemical analysis of pericyte coverage (alpha-smooth muscle actin, alpha-SMA), markers of angiogenesis (CD105, VEGFR-2) and inflammation (human leukocyte antigen-DR, HLA-DR), as suggested in literature. ${ }^{49}$ Preliminary results of this investigation confirmed a solid correlation between the presence of ICG leakage, malignancy and angiogenesis, after correction for HLA-DR expression. ${ }^{50}$ OCTA has recently been proposed as a non-invasive method for visualising and quantifying vessel structure and density within, under and surrounding OS squamous neoplasia. ${ }^{51}$ While no functional vascular parameter was able to be assessed, the use of OCTA allowed the calculation of total tumour vascular density as a potentially useful criterium associated with malignancy. More research is needed integrating deep learning algorithms into vessel analysis for the future clinical application of OCTA to grade OSL.

In conclusion, corneal FA and ICGA enable the quantification and detection of change of CoNV, and the identification of feeder vessels for treatment planning. 


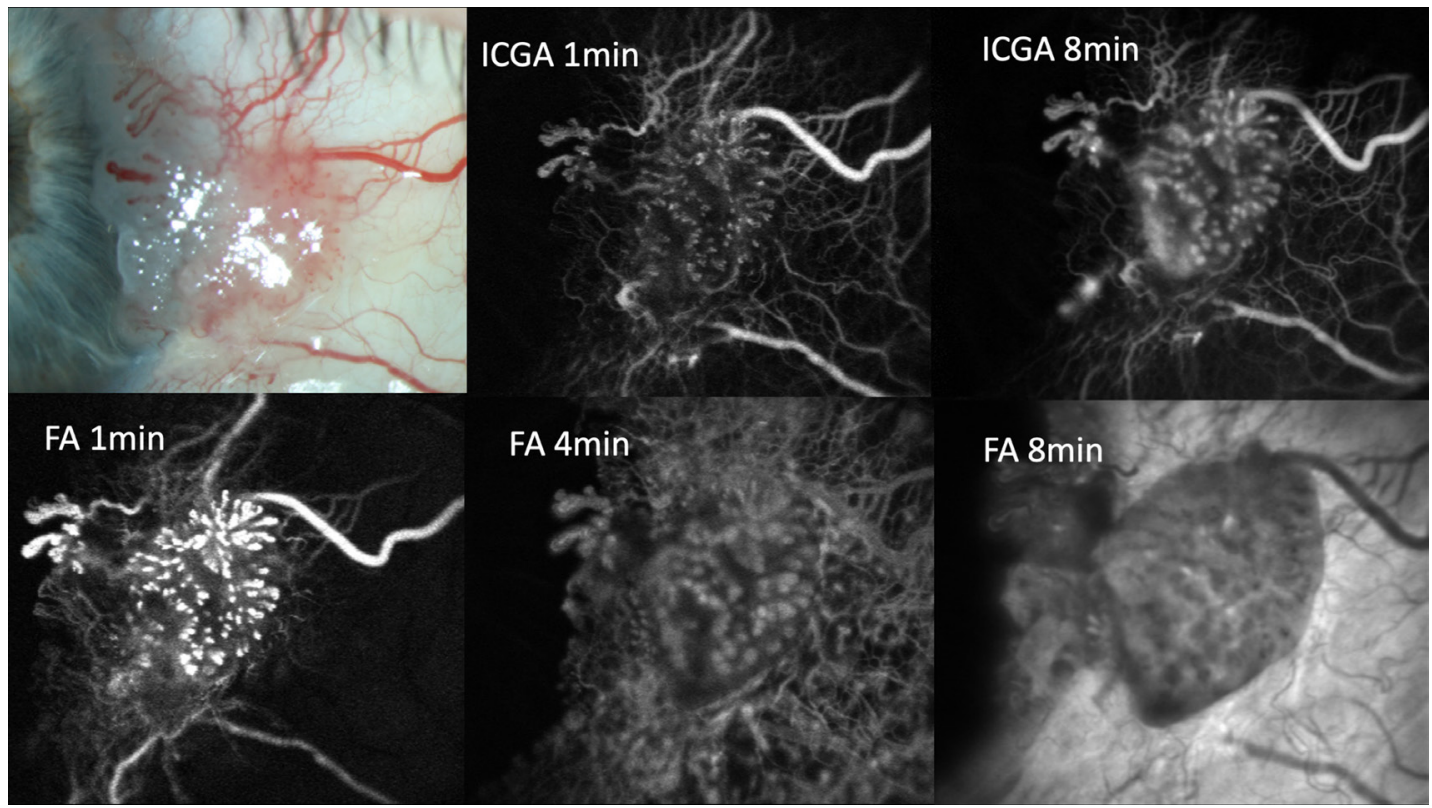

Figure 1 Slit lamp photograph, ICGA and fluorescein angiograms of a case of conjunctival squamous cell in situ carcinoma. Pronounced focal early indocyanine green dye leakage is visible in the upper middle image. Both focal and diffuse indocyanine green leakage are visible in the upper right image. The lower images show diffuse dye leakage in all phases of fluorescein angiography (FA). Note that fluorescein leakage occurs in both tumour and healthy surrounding conjunctiva, while indocyanine green leakage is exclusively confined to the lesion. ICGA. indocyanine green angiography.

ICG leakage serves as direct indicator of vessel maturity and as an indirect indicator of the intracorneal presence of lymphatic vessels for risk assessment of cornea graft recipients. Additionally, ICGA perfusion time is a risk factor for malignancy in OSL. The presence of early ICG leakage from OSL is associated with malignancy and should be regarded as a potentially useful non-invasive indicator of OS tumour angiogenesis and tumour growth.

Funding The authors have not declared a specific grant for this research from any funding agency in the public, commercial or not-for-profit sectors.

Competing interests None declared.

Patient consent for publication Not required.

Provenance and peer review Not commissioned; externally peer reviewed.

Open access This is an open access article distributed in accordance with the Creative Commons Attribution Non Commercial (CC BY-NC 4.0) license, which permits others to distribute, remix, adapt, build upon this work non-commercially, and license their derivative works on different terms, provided the original work is properly cited, appropriate credit is given, any changes made indicated, and the use is non-commercial. See: http://creativecommons.org/licenses/by-nc/4.0/.

ORCID iD

Bernhard Steger http://orcid.org/0000-0002-5316-4661

\section{REFERENCES}

1 Palme C, Ahmad S, Romano V, et al. En-face analysis of the human limbal lymphatic vasculature. Exp Eye Res 2020;201:108278.

2 Romano V, Steger B, Ahmad M, et al. Imaging of vascular abnormalities in ocular surface disease. Surv Ophthalmol 2021;6257:00119-3. doi:10.1016/j.survophthal.2021.05.001

3 Kirwan RP, Zheng Y, Tey A, et al. Quantifying changes in corneal neovascularization using fluorescein and indocyanine green angiography. Am J Ophthalmol 2012;154:850-8.

4 Anijeet DR, Zheng Y, Tey A, et al. Imaging and evaluation of corneal vascularization using fluorescein and indocyanine green angiography. Invest Ophthalmol Vis Sci 2012;53:650-8.
5 Palme C, Romano V, Brunner M, et al. Functional staging of corneal neovascularization using fluorescein and indocyanine green angiography. Trans/ Vis Sci Technol 2018;7:15.

6 Romano V, Steger B, Brunner M, et al. Method for angiographically guided fine-needle diathermy in the treatment of corneal neovascularization. Cornea 2016;35:1029-32.

7 Steger B, Romano V, Kaye SB. Angiographic evaluation of inflammation in atopic keratoconjunctivitis. Ocul Immunol Inflamm 2018;26:685-8.

8 Romano V, Steger B, Brunner M, et al. Detecting change in conjunctival hyperemia using a Pixel densitometry index. Ocul Immunol Inflamm 2019;27:276-81.

9 Brunner M, Steger B, Romano V, et al. Identification of feeder vessels in ocular surface neoplasia using indocyanine green angiography. Curr Eye Res 2018;43:163-9.

10 Palme C, Wanner A, Romano V, et al. Indocyanine green angiographic assessment of conjunctival melanocytic disorders. Cornea 2021. doi:10.1097/ICO.0000000000002681. [Epub ahead of print: 15 Feb 2021].

11 Clements JL, Dana R. Inflammatory corneal neovascularization: etiopathogenesis. Semin Ophthalmol 2011;26:235-45.

12 Bachmann B, Taylor RS, Cursiefen C. Corneal neovascularization as a risk factor for graft failure and rejection after keratoplasty: an evidence-based meta-analysis. Ophthalmology 2010;117:1300-5.

13 Sivak JM, Ostriker AC, Woolfenden A, et al. Pharmacologic uncoupling of angiogenesis and inflammation during initiation of pathological corneal neovascularization. $J$ Biol Chem 2011;286:44965-75.

14 Wuest TR, Carr DJJ. Vegf-A expression by HSV-1-infected cells drives corneal lymphangiogenesis. J Exp Med 2010;207:101-15.

15 Maruyama K, li M, Cursiefen C, et al. Inflammation-Induced lymphangiogenesis in the cornea arises from CD11b-positive macrophages. J Clin Invest 2005;115:2363-72.

16 Maruyama K, Asai J, li M, et al. Decreased macrophage number and activation lead to reduced lymphatic vessel formation and contribute to impaired diabetic wound healing. Am J Pathol 2007;170:1178-91.

17 Hos D, Bukowiecki A, Horstmann J, et al. Transient Ingrowth of lymphatic vessels into the physiologically avascular cornea regulates corneal edema and transparency. Sci Rep 2017;7:7227.

18 Narimatsu A, Hattori T, Koike N, et al. Corneal lymphangiogenesis ameliorates corneal inflammation and edema in late stage of bacterial keratitis. Sci Rep 2019;9:2984. 
19 Coster DJ, Williams KA. The impact of corneal allograft rejection on the long-term outcome of corneal transplantation. Am J Ophthalmol 2005;140:1112-22.

20 Dietrich T, Bock F, Yuen D, et al. Cutting edge: lymphatic vessels, not blood vessels, primarily mediate immune rejections after transplantation. J.i. 2010;184:535-9.

21 Le VNH, Hou Y, Bock F, Cursiefen C, et al. Supplemental Anti Vegf A-Therapy Prevents Rebound Neovascularisation After Fine Needle Diathermy Treatment to Regress Pathological Corneal (LYMPH) Angiogenesis. Sci Rep 2020;10:3908.

22 Salabarria A-C, Koch M, Schönberg A, et al. Topical VEGF-C/D inhibition prevents lymphatic vessel Ingrowth into cornea but does not improve corneal graft survival. J Clin Med 2020;9. doi:10.3390/ jcm9051270. [Epub ahead of print: 28 Apr 2020].

23 Dohlman TH, Omoto M, Hua J, et al. VEGF-trap aflibercept significantly improves long-term graft survival in high-risk corneal transplantation. Transplantation 2015;99:678-86.

24 Bucher F, Bi Y, Gehlsen U, et al. Regression of mature lymphatic vessels in the cornea by photodynamic therapy. $\mathrm{Br} J$ Ophthalmol 2014;98:391-5.

25 Hou Y, Le VNH, Tóth G, et al. Uv light crosslinking regresses mature corneal blood and lymphatic vessels and promotes subsequent high-risk corneal transplant survival. Am J Transplant 2018;18:2873-84.

26 Schaub F, Hou Y, Zhang W, et al. Corneal crosslinking to regress pathologic corneal neovascularization before high-risk keratoplasty. Cornea 2021;40:147-55.

27 Cursiefen C, Maruyama K, Jackson DG, et al. Time course of angiogenesis and lymphangiogenesis after brief corneal inflammation. Cornea 2006;25:443-7.

28 Faraj LA, Said DG, Al-Aqaba M, et al. Clinical evaluation and characterisation of corneal vascularisation. Br J Ophthalmol 2016;100:315-22.

29 Liu S, Romano V, Steger B, et al. Gene-based antiangiogenic applications for corneal neovascularization. Surv Ophthalmol 2018;63:193-213.

30 Palme C, Stoeckl V, Franz N. Indocyanine green dye leakage is an indicator of concomitant corneal haem-and lymphatic vascularization. Cornea 2021

31 Ang M, Cai Y, MacPhee B, et al. Optical coherence tomography angiography and indocyanine green angiography for corneal vascularisation. Br J Ophthalmol 2016;100:1557-63.

32 Brunner M, Romano V, Steger B, et al. Imaging of corneal neovascularization: optical coherence tomography angiography and fluorescence angiography. Invest Ophthalmol Vis Sci 2018;59:1263-9.

33 Folkman J. Tumor angiogenesis: therapeutic implications. $N$ Engl $J$ Med 1971;285:1182-6.

34 Pries AR, Cornelissen AJM, Sloot AA, et al. Structural adaptation and heterogeneity of normal and tumor microvascular networks. PLoS Comput Biol 2009;5:e1000394.
35 Konerding MA, Fait E, Gaumann A. 3D microvascular architecture of pre-cancerous lesions and invasive carcinomas of the colon. $\mathrm{Br} \mathrm{J}$ Cancer 2001;84:1354-62.

36 Konerding MA, Fait E, Gaumann A. 3D microvascular architecture of pre-cancerous lesions and invasive carcinomas of the colon. $\mathrm{Br} \mathrm{J}$ Cancer 2001;84:1354-62.

37 Kukreja I, Kapoor P, Deshmukh R, et al. Vegf and CD 34: a correlation between tumor angiogenesis and microvessel density-an immunohistochemical study. J Oral Maxillofac Pathol 2013;17:367-73.

38 Carmeliet P, Jain RK. Angiogenesis in cancer and other diseases. Nature 2000;407:249-57.

39 Kenawy N, Garrick A, Heimann H, et al. Conjunctival squamous cell neoplasia: the Liverpool ocular oncology centre experience. Graefes Arch Clin Exp Ophthalmol 2015;253:143-50.

40 Damato B, Coupland SE. Conjunctival melanoma and melanosis: a reappraisal of terminology, classification and staging. Clin Exp Ophthalmol 2008;36:786-95.

41 Shields CL, Alset AE, Boal NS, et al. Conjunctival tumors in 5002 cases. comparative analysis of benign versus malignant counterparts. The 2016 James D. Allen lecture. Am J Ophthalmol 2017;173:106-33.

42 Shields CL, Chien JL, Surakiatchanukul T. Conjunctival tumors: review of clinical features, risks, biomarkers, and outcomes-the 2017 J. Donald M. gass Lecture. Asia Pac J Ophthalmol 2017;6:109-20.

43 Krachmer JH, Mannis MJ, Holland EJ. Cornea. 3 edn. Mosby Elsevier, 2011.

44 Brunner M, Steger B, Romano V, et al. Identification of feeder vessels in ocular surface neoplasia using indocyanine green angiography. Curr Eye Res 2018;43:163-9.

45 Pries AR, Cornelissen AJM, Sloot AA, et al. Structural adaptation and heterogeneity of normal and tumor microvascular networks. PLoS Comput Biol 2009;5:e1000394.

46 Sun Y, Hua R. Ocular surface squamous neoplasia: angiographic characteristics and response to subconjunctival/perilesional 5-fluorouracil injections. Drug Des Devel Ther 2019;13:1323-34

47 Palme C, Wanner A, Romano V, et al. Observation of angiographic dye leakage in ocular surface squamous neoplasia. Am J Ophthalmol Case Rep 2020;20:100912.

48 Nagy JA, Benjamin L, Zeng H, et al. Vascular permeability, vascular hyperpermeability and angiogenesis. Angiogenesis 2008;11:109-19.

49 McDonald DM, Choyke PL. Imaging of angiogenesis: from microscope to clinic. Nat Med 2003;9:713-25.

50 Stoeckl V, Palme C, Franchi A. Immunohistochemical vascular correlates to indocyanine green leakage from ocular surface tumors. Sci Rep 2021.

51 Liu Z, Karp CL, Galor A, et al. Role of optical coherence tomography angiography in the characterization of vascular network patterns of ocular surface squamous neoplasia. Ocul Surf 2020;18:926-35. 